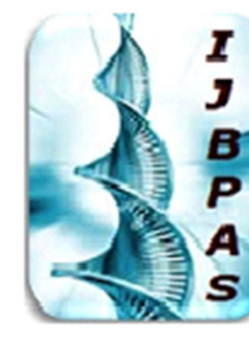

International Journal of Biology, Pharmacy and Allied Sciences (IJBPAS)

'A Bridge Betueen caboratory and QRendo'

www.ijbas.com

\title{
SYNTHESIZE NEW NANOMATERIAL NCC AND NCP FOR DEACIDIFY PAPER MATERIALS
}

\author{
SURAPANENI KRISHNA MOHAN ${ }^{*}$, SACHINGIHAR ${ }^{2}$, R S CHANDOK ${ }^{3}$, \\ MOHAMMED IMRAN ANEES ${ }^{4}$, DHIVYA. $P^{5}$ AND PRAMATHESH MISHRA T $\mathbf{N}^{6}$
}

1: Departments of Biochemistry, Molecular Virology, Research, Clinical Skills \&

Simulation, Panimalar Medical College Hospital \& Research Institute, Varadharajapuram, Poonamallee, Chennai - 600123

2: Assistant Professor in Chemistry at VRAL Govt. Girls Degree College Bareilly, Uttar Pradesh, India

3: Principal, Sri Guru Tegh Bahadur Khalsa College, Jabalpur, Madhya Pradesh, India

4: Pharmaceutical Chemistry at Y.B. Chavan College of Pharmacy, Aurangabad, Maharashtra, India

5: Assistant Professor in Chemistry at Nirmala College For Women, Coimbatore 6: Assistant Professor in Pharmacology at Hygia College of Pharmacy, Lucknow Uttar Pradesh 226020, India

*Corresponding Author: Surapaneni Krishna Mohan; E Mail: krishnamohan.surapaneni@gmail.com

Received 20 ${ }^{\text {th }}$ July 2021; Revised 22 ${ }^{\text {nd }}$ Aug. 2021; Accepted $30^{\text {th }}$ Sept. 2021; Available online $1^{\text {st }}$ Nov. 2021 https://doi.org/10.31032/IJBPAS/2021/10.11.1059

\begin{abstract}
Interior and environmental causes, such as the existence of excessive elements, improper maintenance, dampness, availability of these artifacts to contaminants, lighting, or extreme temps, cause spontaneous degradation of publication historic property pieces. To combat the deterioration of genuine artifacts, it is important to research and execute creative preserving procedures, as well as to develop or synthesizing new goods. The use using nanoparticles for historical property has become more significant as their area as nanocomposites research has progressed during the previous several generations. Similar enthusiasm over new substances paved that way towards an unregulated transference of nanomaterials created for a variety of uses to newspaper restorations, ignoring any potential
\end{abstract}


combinations with the supporting or graphical medium. The goal of this research was to create novel nanotechnology that was specifically designed for the restoration of librarian items. The novel nanostructures were evaluated on experimental newspaper examples as well as real manuscripts to see if they could be used in formal protection procedures that have been validated. This paper outlines the findings of various investigations, underlining the study's good and highly hopeful findings.

\section{Keywords: Optical Phenomenon; Nanoparticles; Nano calcium Disodium; Manufacturing} INTRODUCTION

Its intricacy of the probable interconnections amongst many of the elements comprising the physical pieces: newspaper backing, colors, pigments, textures, and sealants, nothing to include the components employed during depending [1] makes the description of documents, volumes, or graphical artworks difficult. Every creative thing is one-of-akind, and there are no standard procedures for studying these. All conceivable relationships amongst the constituents of the historic property artifact and associated deterioration tendencies must be studied and interpreted. Even though individual difficulties linked to documentation deteriorating have been researched and hypothetically modeled for "perfect" items, perfect substances with particular or well degrading patterns cannot represent "actual" things [2]. Given those grounds, the procedures to be employed may be meticulously selected, and the information gathered with various approaches must be appropriately evaluated to allow the selection of the appropriate preservation process or solution for every item.

Some primary breakdown modes that may develop in tissue are oxidative and hydrolyzed, as was widely recognized. Oxidizing causes the newspaper to lose its stiffness and yellow (due to its production of aldehyde helical doubled atoms, $\mathrm{C}=\mathrm{C}$ doubled securities, in the cellulose networks), as well as acidity or fragility [3]. Neutralization causes the link to split and the newspaper to turn brittle. The ability to understand the type of deterioration that happened in the tissue is extremely essential due to your precision of the restorative procedures. In recent research [4], we used Raman spectrometry for analyzing various damaged newspapers to determine the degrading intermediates. These dissolved sheets were indistinguishable among the good tissues because there was no change in the biochemical architecture in overall viscose. Unsaturated sheets, on the other hand, exhibited substantial changes in the region below $1800 \mathrm{~cm} 1$ [5], where the oxidizing 
produced physiological and architectural alterations in the viscose biopolymer. Its Optical amplitude for maxima is reported to be affected by the pattern's direction about the polarisation of the stimulating beams. Some many distinctive musicians of biopolymer demonstrate differences throughout frequency as a component of filament alignment throughout Raman spectra, however, a strong peak at roughly $1577 \mathrm{~cm} 1$ was often available in the hydrolyzed specimen and also do not alter in brightness with filament alignment and precession, creating this group a great "pointer" of the corrosion method [6-8]. Figure 1 shows how the existence of additional zones helps to comprehend and validate the establishment of operational groupings.

Following determining the type of degrading caused by the tissue [9], the appropriate solution and solvents to use may be selected. The issues with cotton degradation and manipulation procedures on actual artifacts have been explored extensively [10-11] and would not be explored herein. Approved procedures [12] had been added that include the items researched and related use to the librarian and archive collections. Esterification therapies were used to alleviate issues associated with the acidity of the supporting [13].
This so hauntingly of carbon substances entails the production of moisture salt to counteract the acidity bands, i.e., the acetic functionalities. Limestone dioxide has been frequently employed for acetalization in the past, although it has several drawbacks: It becomes irresolvable in liquid (fizzing of carbon gases in inside liquid remedy can be required for disintegration) or many isopropanol; answers can hardly be obtained at decreased concentrations (0.3 gL1), and the workaround must be pristinely fully ready to try to prevent reprecipitation of both moreover sodium; lengthy soaking times are required for acceptable acetalization; Furthermore, watery procedures may not necessarily work with graphical medium [15]. This limestone chloride is used in abundance, rather than in a thermodynamical proportion, and counteract the acidity processes in the tissue while also delivering magnesium if new corrosive processes arise. Numerous organic and manufactured polysaccharides and manmade monomers have been investigated for cleansing, repairing, and reinforcing newspapers.

Several nanoparticles created for various purposes [16] reportedly being "relocated" to newspaper repair in recent decades, while considering any potential detrimental reactions. A goal of this study 
was to create new nanostructures specifically designed for the affirmation and alkalization diagnosis of publications, collections paperwork, and illustration operates of art, to test their attitudes on experimental newsprint specimen and previous files, and to assess their potential use of invalidated authoritative sustainability therapies.

\section{Processing techniques}

All your solutions (Sigma-Aldrich) are commercial purity that was employed exactly as they were given to us. In make distilled freshwater for other everyday procedures, a Milli-Q water machine was employed. Whatman CHR-1 chromatographic material was employed for the scientific materials. The material was then scaled using Crestar C05702, a hydrophilic engineered oats corn-starch that was $10 \% \mathrm{w} / \mathrm{v}$ in solution. Some specimens were fermented for approximately 15 minutes by inhaling strong corrosive solution fumes. Several damaging \&noninvasive investigations were performed on those materials. The sheets, which were scaled without collagen, were made from 100 percent flax strands and the words were penned in metal paint. Several explosive \&non-invasive investigations were performed on those materials. Purely non-invasive procedures were used to examine the material. $\mathrm{pH}$ readings were taken by protocol. A Minolta Chroma Meters CR22 instrument was used to take spectrometric observations taken.

This physical assessment of these nanomaterials was carried out using a Zeiss LEO1550 scanned electrons microscope/energy arbitrary imaging system connected with an Edwards Scanner Coat K550X spray applicator.. A lengthy collection period was decided to show that the quantity of the components included in the underlying paper had not changed significantly.

\section{RESULTS AND DISCUSSION}

Inside a distinct chapter, the deployment of several nanomaterials, specifically produced for use on libraries items, will be explored. $\mathrm{CaCO} 3$ has been frequently implemented in this historical material context to deacidify material that has been degraded by the inclusion of ferrous dyes or by exposure to the outside atmosphere [17]. The ability to disperse a concentrated excellent deacidified under unique solutions is the problem in creating nanomaterials. When comparing against market goods, the Tor Vergara School chemistry laboratory devised a unique manufacturing process that resulted in nano carbonates with a distinct shape. The biochemical method for the novel nano$\mathrm{CaCO} 3$ ensures excellent cytocompatibility for final customers such as painters and 
preservationists, and the environmental chemicals technique ensures that the procedure is eco-friendly [18]. Furthermore, the unique microstructure generated provides for data reaches into the mass of the material as well as liquid or gaseous.

Nano Carbonate atoms have previously been used in newspaper repair until this work, to our awareness. Only micro (or magnesium) sulfates have been suggested, but it is worth noting that the approved techniques for ethnic legacy particles on documents granted throughout Milan [19] prohibit the use of halides due to the alloying elements' too elevated segmental $\mathrm{pH}$, which can cause $\beta$-alkoxy abolition and resulting pyrolysis.

A quantity of 3 percent w/v or nano carbonate with propane-2-or were employed during the testing on genuine papers materials, while this solution was administered by sweeping it from the rectifier face of the paper. The infiltration was sufficient to eliminate this need for an additional therapy on the reverse surface. Early findings revealed a magnesium absorbency of around $0.6 \mathrm{~g}$ per $100 \mathrm{~g}$ of tissue. The project is currently ongoing. The observations, as shown in Table 1, revealed a $\mathrm{pH}$ rise of more than 4 units for either the material or the acidic ink following the procedure, with little to no change in coloring.

Micro Charcoal was also used in the earliest recorded restoration of an authentic antique ruined papyrus to supply a calcareous resource to extend the team's durability and predicted lifespan. The pigments used on the paper, steel paint and uraninite, had no detrimental interactions with the graphical medium, according to Spectral data.

\section{Calcium Phosphate}

Immiscible methods when preserving authentic records are frequently required by the book, archive, and visual pieces of art archivists to minimize the breakdown or migrating of the graphical medium and the destruction of the printed imprint. Furthermore, immiscible chemicals enable working on unbound manuscripts while preserving the unique binders. Methodologies and materials were examined in a scientific effort to produce successful deacidification inside an immiscible solution, with methanol as the solution of choice because historically adhesives employed for newspaper manufacture are intractable in this liquid. When processing alkaline sheets containing a 3.5 percent $\mathrm{w} / \mathrm{v}$ quantity of calcium propanoate, excellent effects were produced. The results of scientific 
specimens processed in the ethanol solution are presented in Table 2.

\section{Nano-Calcium phosphate}

Following the positive findings achieved using polyphase sodium propanoate in freshwater and alcohols mixtures, it was determined to investigate the potential of obtaining magnesium propanoate nanomaterials. That is important to note that this method and combination have rarely been attempted previously. Working with valproic acids over an aqueous solution, another novel polycrystalline membrane's theme production method was used to make magnesium nano propanoate. This prototype production procedure may be broken down into 2 stages: predisposed chemicals oxidizing and electrical bioactivity of biologically generated antecedents. Figure 2 depicts a flowchart of a method.

With such a situation, as with Micro Charcoal, the deacidified could be dissolved in a solution that couldn't absorb regular calcareous propanoate. A proportion of 3 percent $\mathrm{w} / \mathrm{v}$ of nano propanoate in propane-2-or was employed for all testing on authentic papers, and the solution was administered by sweeping it from the rectifier face of the materials. Table 3 illustrates the outcomes collected.
For this case, too, the incision proved sufficient to prevent additional therapy on the reverse surface. The findings indicated a $\mathrm{pH}$ rise of greater than $3 \mathrm{pH}$ levels for the newspaper and greater than 5 $\mathrm{pH}$ levels for the corrosive ink, with little to no change in coloring other than a slight elevation in brightness.

\section{Nanographene effect as reinforcements}

Several consecutive mechanical electrochemicals processes were used that make graphite nanofibers just within Tor Vergara College scientific laboratory. In the first phase, strongly orientated pyrolysis process graphene (HOPG) was mechanically exfoliated employing a grinder and rainwater or similar isopropanol as the operating environment. Following the 2nd stage, the graphite strips were electrochemically degraded and physically separated with their HOPG sheets.

\section{Raman Effect}

During \& following these procedures, experimental \& genuine material specimens with associated pigments were examined Figures 3 and 4 illustrate some Raman wavelengths.

Their observations indicated that the calcium concentration in the papers increased and that there were no detrimental interactions with the graphical medium since other spectrums stayed unchanged after the intervention. 


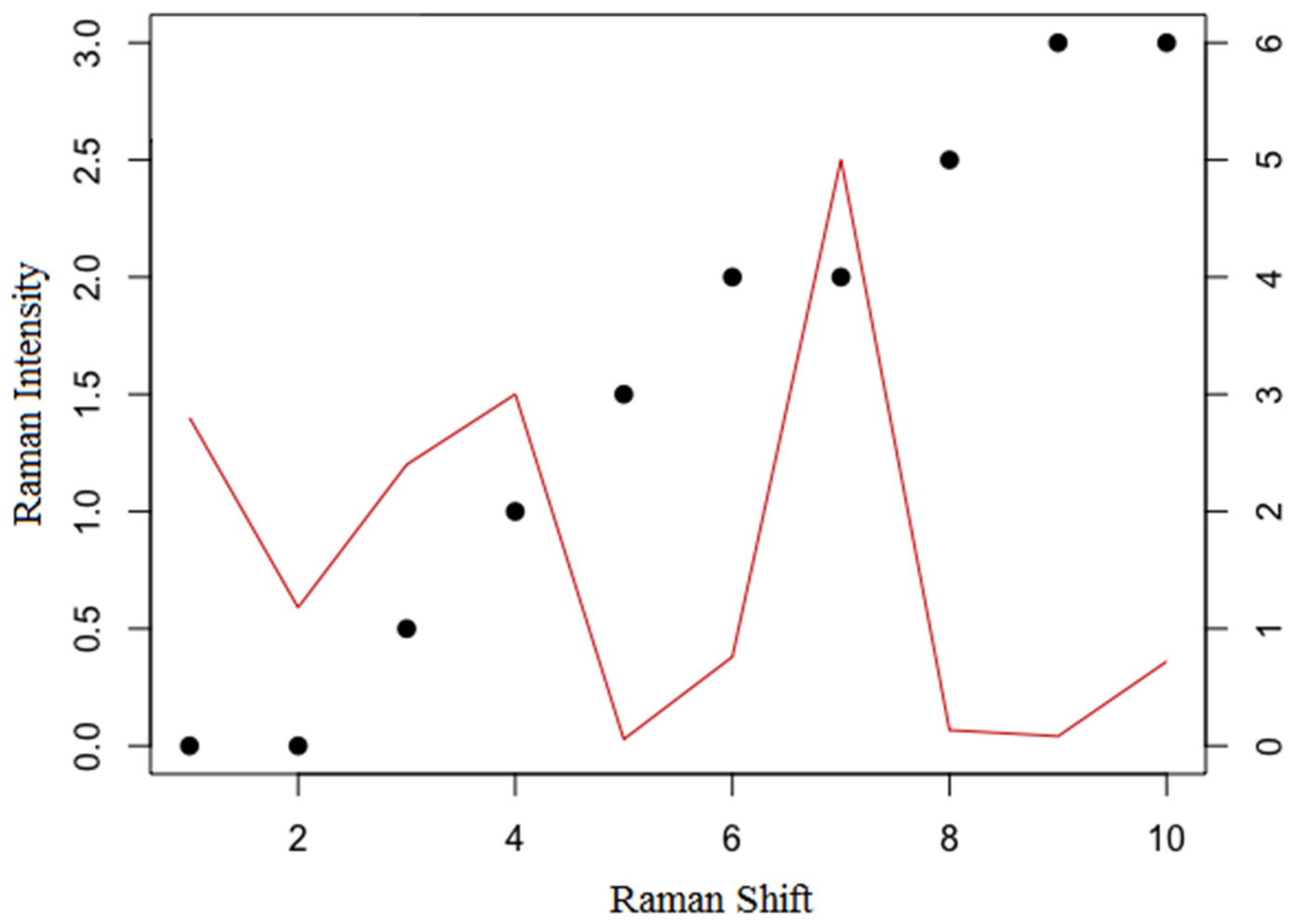

Figure 1: Cellulose chain of Raman Spectra

Table 1: Original documents were treated with nano-calcium carbonate in propan-2-ol

\begin{tabular}{|c|c|}
\hline pH before Treatment & pH after treatment \\
\hline $\begin{array}{c}\text { Paper: } 7.5 \pm 0.2 \\
\text { Ink: } 6.2 \pm 0.2\end{array}$ & $\begin{array}{l}\text { Paper: } 11.6 \pm 0.2 \\
\text { Ink: } 8.9 \pm 0.2\end{array}$ \\
\hline Prior to treatment, colour coordinates & After treatment, colour coordinates \\
\hline $\begin{array}{c}\text { Paper: } \\
\mathrm{L}=92 \pm \mathbf{0 . 1 3} \\
\mathbf{a}=+0.07 \pm 0.01 \\
\mathbf{b}=+12 \pm 0.19 \\
\text { Ink: } \\
\mathbf{L}=\mathbf{6 4} \pm \mathbf{2 . 3 6} \\
\mathbf{a}=+\mathbf{2} \pm \mathbf{0 . 8 6} \\
\mathbf{b}=+15 \pm \mathbf{0 . 5 3}\end{array}$ & $\begin{array}{c}\text { Paper: } \\
\mathbf{L}=\mathbf{9 1} \pm \mathbf{0 . 1 2} \\
\mathbf{a}=+\mathbf{0 . 1 8} \pm \mathbf{0 . 0 2} \\
\mathbf{b}=+\mathbf{1 1} \pm \mathbf{0 . 1 8} \\
\text { Ink: } \\
\mathbf{L}=\mathbf{6 5} \pm \mathbf{2 . 3 7} \\
\mathbf{a}=+3 \pm \mathbf{0 . 8 3} \\
\mathbf{b}=+12 \pm \mathbf{2 . 2 6}\end{array}$ \\
\hline
\end{tabular}

Table 2: Calcium propanoate in ethanol treatment of laboratory paper samples

\begin{tabular}{|c|c|}
\hline pH before Treatment & pH after treatment \\
\hline $\begin{array}{c}\text { Control Paper: } 6.2 \pm 0.2 \\
\text { Acidic Paper: } 5.3 \pm 0.2\end{array}$ & $\begin{array}{c}\text { Control Paper: } 9.8 \pm 0.2 \\
\text { Acidic Paper: } 8.7 \pm \mathbf{0 . 2}\end{array}$ \\
\hline Prior to treatment, colour coordinates & After treatment, colour coordinates \\
\hline $\begin{array}{c}\text { Control Paper: } \\
\mathbf{L}=98 \pm 0.13 \\
\mathbf{a}=\mathbf{- 0 . 4 1} \pm \mathbf{0 . 0 1} \\
\mathbf{b}=+\mathbf{0 . 6 1} \pm \mathbf{0 . 1 9} \\
\text { Acidic Paper: } \\
\mathrm{L}=\mathbf{9 4} \pm \mathbf{0 . 1 2} \\
\mathbf{a}=\mathbf{- 0 . 7 6} \pm \mathbf{0 . 0 6} \\
\mathrm{b}=+3 \pm \mathbf{0 . 5 2}\end{array}$ & $\begin{array}{c}\text { Control Paper: } \\
\mathbf{L}=\mathbf{9 6} \pm \mathbf{0 . 1 8} \\
\mathbf{a}=\mathbf{- 0 . 4 7} \pm \mathbf{0 . 0 3} \\
\mathbf{b}=+\mathbf{0 . 1 4} \pm \mathbf{0 . 0 4} \\
\text { Acidic Paper: } \\
\mathbf{L}=\mathbf{9 5} \pm \mathbf{0 . 1 2} \\
\mathbf{a}=\mathbf{- 0 . 6 7} \pm \mathbf{0 . 0 4} \\
\mathbf{b}=+\mathbf{1 . 9 7} \pm \mathbf{0 . 0 2}\end{array}$ \\
\hline
\end{tabular}




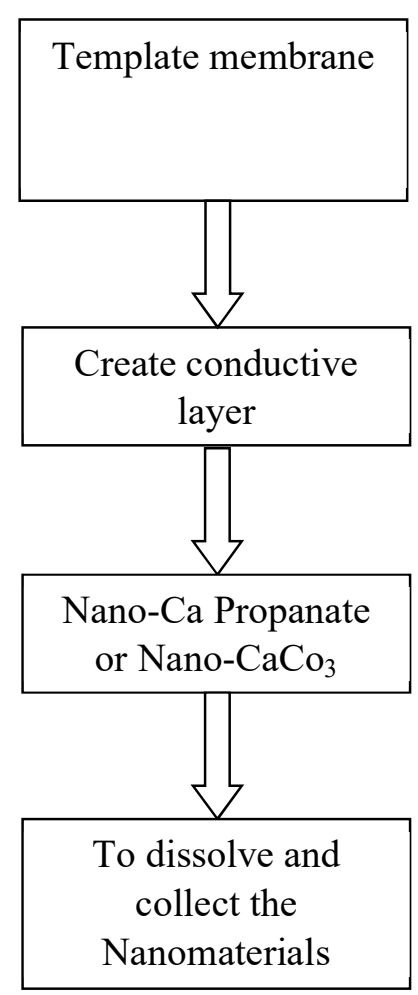

Figure 2: For the nanomaterials mentioned in the study, an electrochemical template synthesis method was used

Table 3: Original documents were treated with nano-calcium propanoate in propan-2-ol $\left(1^{\text {th }}\right.$ Century $)$

\begin{tabular}{|c|c|}
\hline pH before Treatment & pH after treatment \\
\hline $\begin{array}{c}\text { Paper: } 6.5 \pm 0.2 \\
\text { Ink: } 4.2 \pm 0.2\end{array}$ & $\begin{array}{l}\text { Paper: } 10.5 \pm 0.2 \\
\text { Ink: } 9.9 \pm 0.2\end{array}$ \\
\hline Prior to treatment, colour coordinates & After treatment, colour coordinates \\
\hline $\begin{array}{c}\text { Paper: } \\
\mathbf{L}=\mathbf{9 3} \pm \mathbf{0 . 5 2} \\
\mathbf{a}=\mathbf{- 0 . 0 5} \pm \mathbf{0 . 0 1} \\
\mathbf{b}=+\mathbf{1 3 . 2 5} \pm \mathbf{0 . 4 4} \\
\text { Ink: } \\
\mathbf{L}=\mathbf{7 2} \pm \mathbf{0 . 0 6} \\
\mathbf{a}=+\mathbf{4 . 7 6} \pm \mathbf{0 . 6 4} \\
\mathbf{b}=+\mathbf{1 6 . 2 5} \pm \mathbf{0 . 5 9}\end{array}$ & $\begin{array}{c}\text { Paper: } \\
\mathbf{L}=\mathbf{9 3} \pm \mathbf{0 . 1 4} \\
\mathbf{a}=\mathbf{- 0 . 0 8} \pm \mathbf{0 . 0 3} \\
\mathbf{b}=+\mathbf{1 3} \pm \mathbf{1 . 0 6} \\
\text { Ink: } \\
\mathbf{L}=\mathbf{7 8 . 0 2} \pm \mathbf{0 . 0 2} \\
\mathbf{a}=+\mathbf{3 . 5 6} \pm \mathbf{0 . 6 5} \\
\mathbf{b}=+\mathbf{1 5} \pm \mathbf{0 . 6 5}\end{array}$ \\
\hline
\end{tabular}

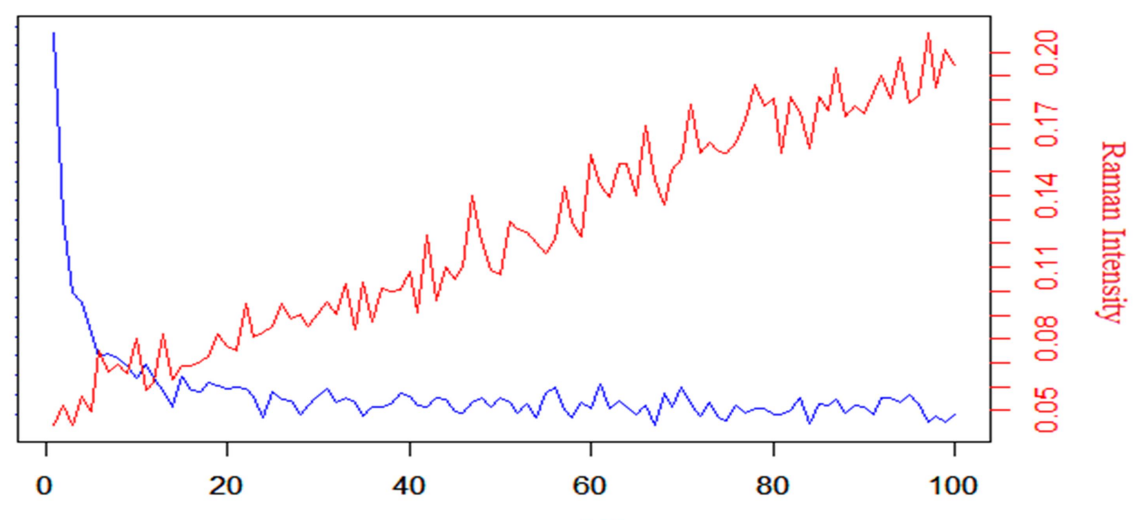

Raman Shift

Figure 3: Raman Spectra of the exciting line without baseline correction 


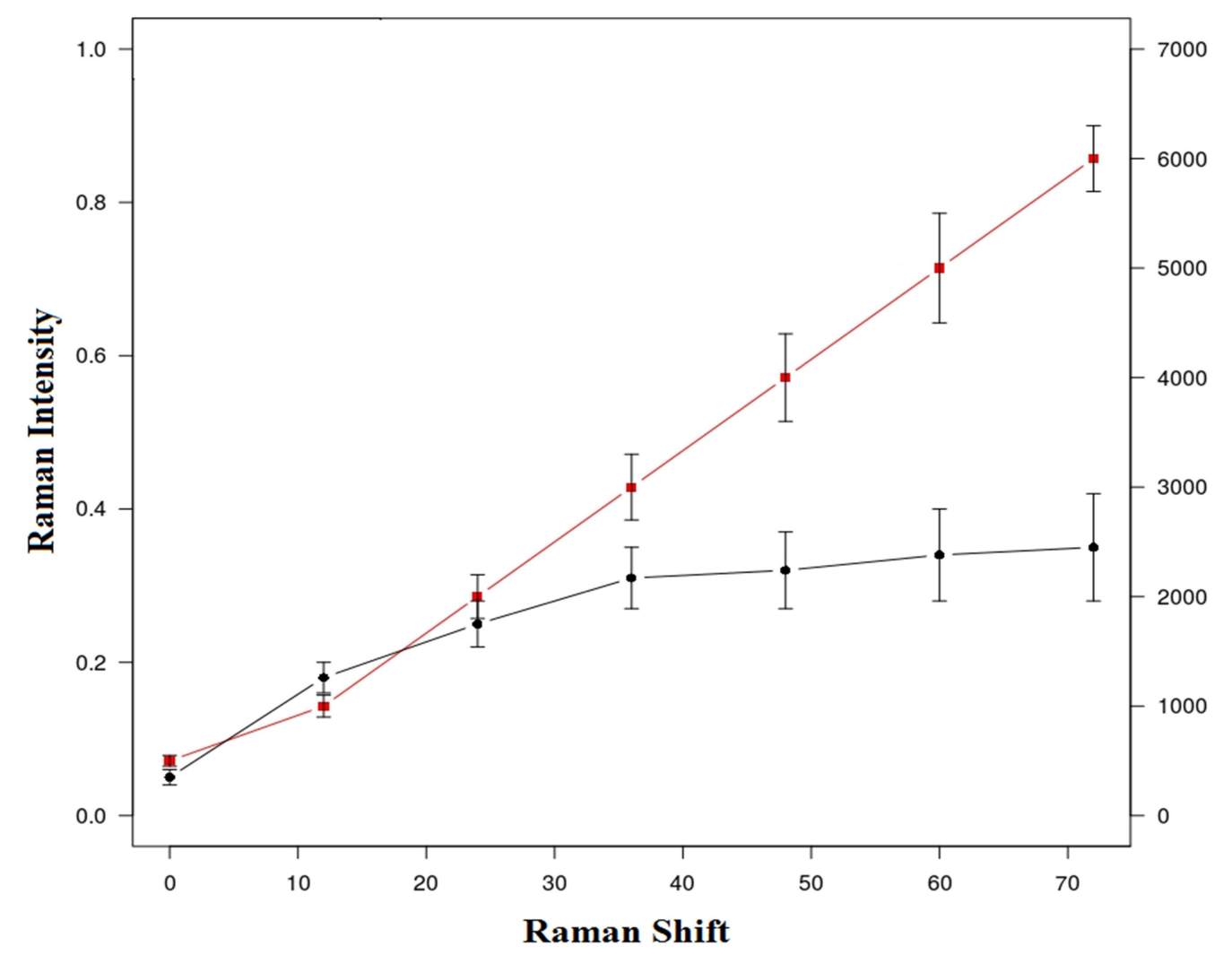

Figure 4: Raman Spectra of comparison with a standard calcite spectrum

\section{CONCLUSIONS}

Their researchers present a unique restoration methodology in this paper that includes the focused deployment of technologies (such as -Raman spectrometry) as well as the development of novel goods and procedures. The recently manufactured calcium carbonate and calcium propionate nanomaterials offer a secure restoration option for historical paintings on parchment since they are nonaggressive to the supporting and graphical medium, and they may be destroyed in unusual solutions. These novel nanoparticles penetrate deeply into the degraded substance, ensuring the correct
$\mathrm{pH}$ reaction for an extended period of period and therefore ensuring its esterification treatment's long-term durability. Furthermore, nanomaterials substances have great promise due to both biomaterials with "finished" as well as inherent environmental friendliness, which is linked to the Green Chemical methodology.

\section{REFERENCES}

[1] Franco-Castillo I, Hierro L, Jesús M, Seral-Ascaso A, Mitchell SG. Perspectives for antimicrobial nanomaterials in cultural heritage conservation. Chem. 2021 Feb 10. 
[2] Fouda A, Abdel-Maksoud G, Abdel-Rahman MA, Eid AM, Barghoth MG, El-Sadany MA. Monitoring the effect of biosynthesized nanoparticles against biodeterioration of cellulose-based materials by Aspergillus niger. Cellulose. 2019 Jul; 26(11): 658397.

[3] Mazzoli R, Giuffrida MG, Pessione E. Back to the past: "find the guilty bug-microorganisms involved in the biodeterioration of archeological and historical artifacts". Applied microbiology and biotechnology. 2018 Aug; 102(15): 6393-407.

[4] Dr.P.Sivakumar, "Analytical framework to build predictive and optimization function from manufacturing industry sensor data using cross-sectional sharing", Big Data,2021 (SCI)

[5] Dr.P.Sivakumar, "Improved Resource management and utilization based on a fog-cloud computing system with IoT incorporated with Classifier systems", Microprocessors and Microsystems, Jan 2021 (SCI).

[6] Ranjeeth, S., Latchoumi, T. P., \& Paul, P. V. (2020). Role of gender on academic performance based on different parameters: Data from secondary school education. Data in brief, 29, 105257.

[7] Venkata Pavan, M., Karnan, B., \& Latchoumi, T. P. (2021). PLA-Cu reinforced composite filament: Preparation and flexural property printed at different machining conditions. Advanced Composite Materials, https://doi. org/10.1080/09243046.2021, 19186 08 .

[8] Ferrari P, Chelazzi D, Bonelli N, Mirabile A, Giorgi R, Baglioni P. Alkyl carbonate solvents confined in poly (ethyl methacrylate) organogels for the removal of pressure-sensitive tapes (PSTs) from contemporary drawings. Journal of Cultural Heritage. 2018 Nov 1; 34: 227-36.

[9] Simion CA, Cozac MM, Florea NM, Gaza O, Stanciu IM, Pacesila DG, Ilie MV, Manailescu C, Stanculescu I, Robu A. Multidisciplinary Studies on Canvas Nature of Paintings at IFIN-HH Romania. Journal of Cultural Heritage. 2021 Nov 1; 52: 107-17.

[10] Lisuzzo L, Cavallaro G, Milioto S, Lazzara G. Halloysite nanotubes filled with $\mathrm{MgO}$ for paper reinforcement and deacidification. 
Applied Clay Science. 2021 Nov

1; 213: 106231.

[11] Baglioni P, Chelazzi D, Giorgi R. Nanotechnology and Nanoscience in Conservation. The Encyclopedia of Archaeological Sciences. 2018 Oct 10:1-7.

[12] Oriola-Folch M, Campo-Francés G, Nualart-Torroja A, RuizRecasens C, Bautista-Morenilla I. Novel nanomaterials to stabilize the canvas support of paintings assessed from a conservator's point of view. Heritage Science. 2020 Dec; 8(1): 1-2.

[13] Micheli L, Mazzuca C, Missori M, Teodonio L, Conte AM, Pulci O, Arcadipane L, Dominijanni S, Palleschi A, Palleschi G, Iannuccelli S. Interdisciplinary approach to develop a disposable real time monitoring tool for the cleaning of graphic artworks. Application on "le Nozze di Psiche". Microchemical Journal. 2018 May 1; 138: 369-78.

[14] Rani, D. R., Dhulipala, N., Pinniboyina, T., \& Chattu, P. (2011). Outlier detection for dynamic data streams using weighted k-means. International Journal of Engineering Science and Technology, 3(10), 74847490.

[15] Rani, D. R., \& Geethakumari, G. (2020). Secure data transmission and detection of anti-forensic attacks in cloud environment using MECC and DLMNN. Computer Communications, 150, 799-810.

[16] Bicchieri M, Valentini F, Calcaterra A, Talamo M. Newly developed nano-calcium carbonate and nano-calcium propanoate for the deacidification of library and archival materials. Journal of analytical methods in chemistry. 2017 Dec 26; 2017.

[17] David ME, Ion RM, Grigorescu RM, Iancu L, Andrei ER. Nanomaterials used in conservation and restoration of cultural heritage: an up-to-date overview. Materials. 2020 Jan; 13(9): 2064

[18] Wang S, Yang X, Li Y, Gao B, Jin $\mathrm{S}$, Yu R, Zhang $\mathrm{Y}$, Tang $\mathrm{Y}$. Colloidal Magnesium Hydroxide Nanoflake: One-Step SurfactantAssisted Preparation and PaperBased Relics Protection with Long-Term Anti-Acidification and Flame-Retardancy. Journal of Colloid and Interface Science. 2021 Sep 9. 
[19] Mamdouh A. Importance of using Nanomaterials in Preservation of Oil Paintings for Achieving Required Sustainability.
International Design Journal. 2020

Apr 1; 10(2): 305-10. 